\title{
RESPONSIVE WEB DESIGN AND \\ COMPARATIVE ANALYSIS OF DEVELOPMENT FRAMEWORKS
}

\author{
Bülent Onur TURAN \\ Mimar Sinan Fine Arts University, Turkey \\ boturan@gmail.com \\ Kemal ŞAHIN \\ Mimar Sinan Fine Arts University, Turkey \\ kemalsahin@gmail.com
}

\begin{abstract}
Developments that have been realized regarding software and hardware in the communications industry have led to compulsory developments in approaches to website designs. The problem of providing and sustaining compatibility of websites with devices on the market has led to the development of new approaches. As a result of this situation, a responsive web design approach that solves the problem of hardware compatibility has been developed in addition to software and software development methods that allow for the application of this approach. This design approach, which has been more frequently used since 2011 , has been preferred by both individuals and companies because it is more sustainable and easier to use. Responsive web design principles and the reasons behind their necessity have been analyzed in this paper. Furthermore, the frameworks that have been developed based on this design approach were analyzed and their characteristics and qualities were compared in reference to responsive web design principles. The criteria necessary for choosing a powerful and effective framework have been laid out.
\end{abstract}

Keywords: web design, responsive design, responsive web design frameworks, media queries

\section{UYUMLU WEB TASARIMI VE GELIŞEN ALTYAPILARIN KARŞILAŞTIRMALI ANALIZI}

ÖZ

İletişim sektöründe gerçekleşen yazılım ve donanım ile ilgili gelişmeler web sitelerinin tasarım yaklaşımlarında da gelişmenin zorunluluğunu doğurmuştur. Web sitelerinin, piyasada bulunan cihazlar ile uyumluluğunun sağlanması ve sürdürülmesi problemi yeni yaklaşımların geliştirilmesini sağlamıştır. Bu durum sonucunda donanım uyumu sorununu çözen duyarlı web tasarımı yaklaşımı ve bu yaklaşımın uygulanmasını sağlayan yazılım ve yazılım geliştirme yöntemleri ortaya çıkmıştır. 2011 yılından beri kullanımı sıklaşan bu tasarım yaklaşımı firmalar ve kişiler tarafından sürdürülebilirliği artırdığı ve kullanım kolaylığg sağladığı için tercih edilmektedir. Bu makale kapsamında duyarlı web tasarımının prensipleri, ilkeleri ve neden ihtiyaç duyulduğu irdelenmiştir. Ayrıca, bu tasarım yaklaşımı temel alınarak geliştirilen çatılar incelenmiş, sahip olduğu özellikler ve nitelikler, duyarlı web tasarım ilkeleri doğrultusunda kıyaslanmıştır. Güçlü ve etkin bir çatı seçimi için gerekli olan kriterler çıkartılmıştır.

Anahtar Kelimeler: web tasarımı, duyarlı, akışkan, duyarlı web tasarımı çatıları, medya sorgusu

\section{INTRODUCTION}

Web design approaches and technologies undergo continual dynamic changes. The reason behind this change is the developmental tools entering the market at short intervals and the diversity of devices on 
the market. In order to create an effective website, it is very important today to adopt design approaches that are inclusive and in line with our times.

In the art of painting, all works are depicted on fabric, paper or a surface. When the work of art is completed, those who look at that work see something of the same size and proportion. When web designers begin to work, the beginning stages resemble those of artists. They create an empty web page of a specific size and begin to design. When the design is completed they face a difficulty. The appearance that the website visually presents to users may differ according to the size and resolution of the device with which the user is viewing that website. This problem was ignored during the first years of the Internet when differences in screen dimensions were not big. However, today when there are so many different sized devices, the solution of this problem has become mandatory. One approach in solving this problem is "Responsive Web Design". Responsive web design is a new topic that is being used with increasing frequency and is arousing interest.

\section{What is Responsive Web Design?}

Responsive Web Design is a form of web design in which user interfaces are sensitive to screen resolution. Thus all devices that can be connected to the Internet provide ease of navigation for the user regardless of the device and its resolution properties. The device may be a personal computer, telephone, tablet, television, vehicle or almost anything in the near future. In other words, it is a design approach used to provide the same or very similar user experiences for different usage scenarios.

There are two basic components in the responsive web design approach. These components are the contents of the website and the website itself which contains the contents. The dimensions of the website are determined by means of software in accordance with the resolution and dimensions of the screen in which the website is displayed. Following the defining process, the contents are inserted into this page. Contrary to previous design approaches, since the display of the contents is dynamic, the user experience provided by the website will be similar or the same even if the devices are different. This situation increases employability. A user friendly website is a result that companies and individuals alike expect. Furthermore, employability is a key factor in web design and marketing strategies for companies [1] In this situation, the contents can be thought of as water and the website as a vessel containing it. As the shape of the vessel changes, so does the shape of the water [2].

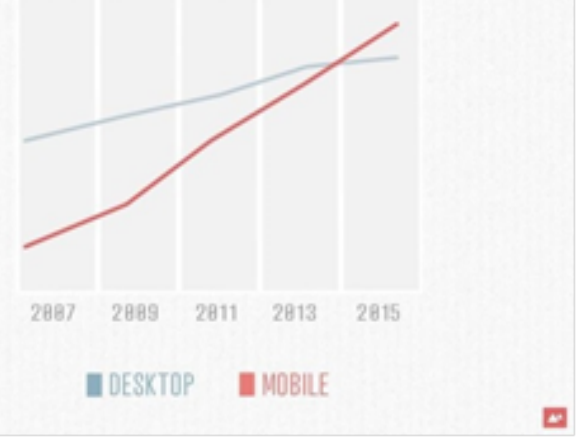

Figure 1 The Increase in Usage of Mobile and Desktop Devices between 2009-2015

\section{Reasons Why Responsive Web Design Is Needed}

With the increase in the use of the Internet and the devices with which Internet is accessed, the problem of websites appearing differently on different screens began. This has affected both users and website owners. The first solution thought of for this problem was designing different websites for each type of screen and presenting these websites to users in accordance with the screens they have. Although this solution was effective in the beginning, it increased the cost of development and sustainability. Thus it was adapted only by companies and individuals who could allocate greater amounts for developmental costs in their budgets. This solution has become insufficient because the resolution properties and dimensions of devices connectable to the Internet have undergone great diversity in the past ten years. Designing and updating websites for tens of different resolution properties requires great amounts of money, manpower and repetition of work definitions.

This necessity can be seen in the statistics regarding the increase in the use of the Internet and its relation to the diversity of devices. The use of mobile Internet is increasing at a rate of eightfold in 
comparison to Internet use with desktops [3]. Today one out of every five people use the Internet on a daily basis and $25 \%$ of the people who use the Internet carry out their entire search on mobile devices [4]. In addition to this statistical information, the variety of multimedia in use is also undergoing change and growing in size. In order for the industry to keep up with this progress there is a need for a dynamic design approach. One of these approaches is responsive web design.

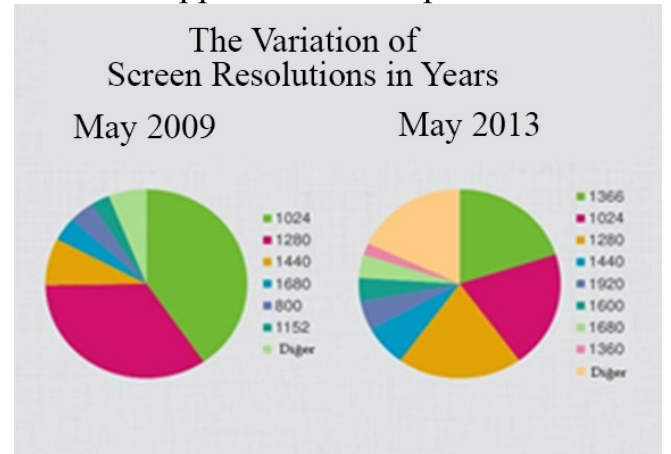

Figure 2 Variation of Screen Resolution in Usage between May 2009-May 2013

\section{PRINCIPLES of RESPONSIVE WEB DESIGN}

The aim of the responsive design approach is to provide easy to use, user friendly websites which have similar appearances on all screens. The principles and application methods necessary to actualize this aim are more complex in comparison to traditional website development methods. As a result of this complexity, it is more time consuming and higher skilled programmers and designers need to be employed. In order to overcome these difficulties and reduce the time involved in designing, a systematic course with specific components should be followed. In order to effectively and easily actualize responsive web design certain principles need to be adhered to during the design process. Abiding by these principles during the design process directly affects the quality of the resulting product.

\section{Responsive Web Template}

One of the differences between older style and responsive web design is the format of the templates used. In the old style web design approach, the breaking points of the connections among the components are defined on a template of fixed size whereas in responsive web design, these breaking points are defined by flexible ratios thus aiming for fluidity in display[5]. Responsive web design templates are shaped similar to rubber and take the shape of the screen on which they will be displayed. The usage of the multimedia displayed is also different. As queries are renewed on different sized screens, this process is actualized in accordance dynamically. As a result of this approach, continuity and fluidity of the displayed components is provided. Examples of responsive web templates are shown in Figures 2.1.1.1 and 2.1.1.2.

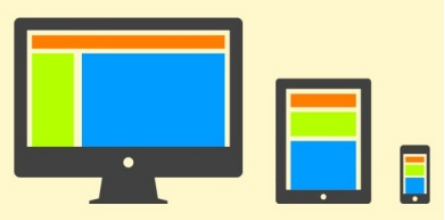

Figure 3 Responsive Web Design Template

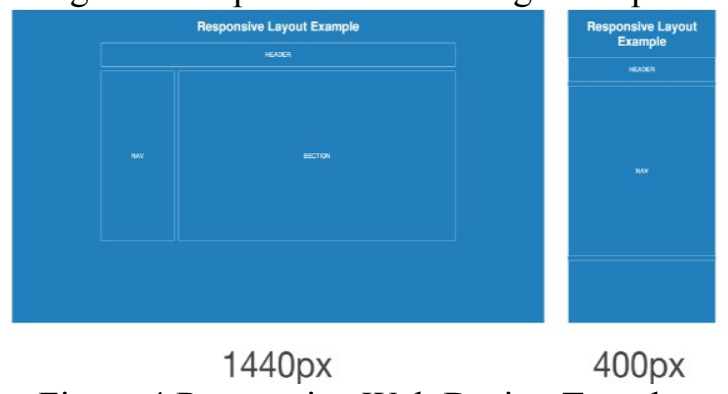

Figure 4 Responsive Web Design Template 


\section{Responsive Web Design Formula}

When preparing a template, there is a formula for rendering flexibility and finding side spaces and fillings with relative numbers. The dimensions of the target component are calculated according to the segment it is located in. In this formula, to find the necessary ratio, the width of the target component is divided by the width of the segment it is located in. For example, in a screen of 1000 pixels, if left and right segments are defined as $25 \%$ and $75 \%$, respectively, these segments will be viewed as 250 pixels and 750 pixels. The change in the dimensions of the screen will lead to a dynamic renewal in the calculation of the dimensions of these segments.

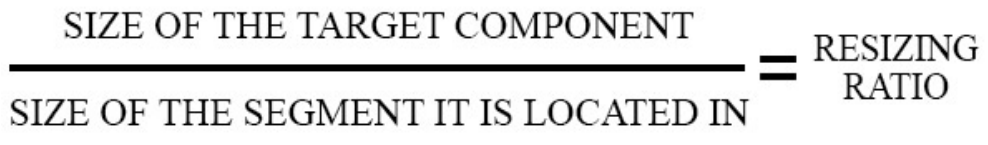

Figure 5 Responsive Web Design Formula

\section{Flexible Side Spaces and Fillings}

When creating responsive web design templates, all values should be given in ratios. The purpose of this process is to present the user with a similar interface even if the properties of the screen in view change. If side spaces and fillings are calculated in pixels, unwanted side spaces and fillings will appear. In order to avoid this situation, these components should be defined as ratios. There are two things that have to be taken into account in the defining process. (a) When defining a responsive side filling for a particular component, the dimensions of the upper component that includes that particular component should be taken as the dimensions of the segment it is located in. (b) When defining a responsive area for a component, the size of the component should be calculated as the size of the segment that component is located in.

\section{Viewports}

Viewport is the name given to all areas on a screen except the routing elements and fixed menus. The dimensions of all the components and templates on the viewport are calculated with the dimensions of the viewport. In order to carry out this calculation, the "viewport" parameter in the $<$ Meta $>$ HTML tag is used. Since the screen sizes of mobile devices are small, the "viewport" parameter is used differently in desktops than it is in mobile devices. This situation is necessary to avoid possible problems. The reason problems occur is that the pixels used in devices are not standardized with regard to CSS (Cascading Style Sheets) pixels.

In order to be able to use viewports effectively, two different concepts need to be examined: template viewport and visual viewport. A template viewport is the unchanging dimension of the device pixels despite the changes in the level of magnification and the location on the screen. The visual viewport is the dimension of the pixels changing according to the image being displayed[6]. Some information on the visual viewport can be found in Figure 2.1.4.1.

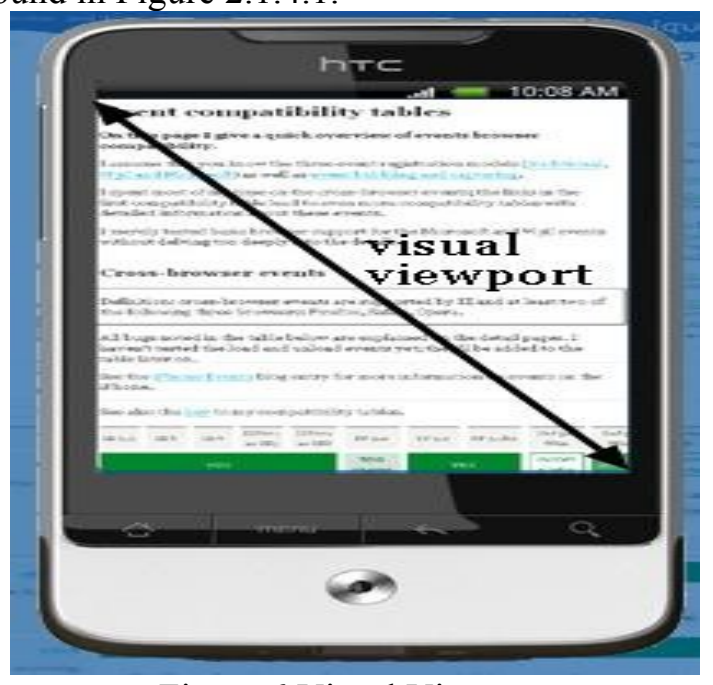

Figure 6 Visual Viewport 


\section{Multimedia Queries}

Multimedia queries are a type of query that enables more than one CSS to be assigned to an element for one specific kind of view. The screen type of the device, which makes up the contents, facilitates changing the styles according to their properties, including width, height, direction, and even resolution.

They are generally used in increasing the responsiveness of website designs in which CSS adjustmentshave been made for more than one screen size. These types of queries enable designers to develop websites that can be read more easily on screens having different resolution properties. Furthermore, these queries enable mobile and desktop website development processes to be united so that two websites can effectively be designed simultaneously [7]. The code rules of multimedia queries show similar behavior no matter what the properties of the device are, thus enabling the code written to be independent of the devices. There are four basic components of multimedia queries: multimedia specifier, multimedia properties for the target device, logical key words and CSS rules. The breaking points are determined by CSS rules and show the places where multimedia queries are enabled [8].

\section{Responsive Typograph}

The actual reason that responsive typography is used is to enable an increase in the ease of reading material written on websites despite the differences in devices. The device may be any of the mobile devices or a desktop computer. One of the topics that must be kept in mind is the distance between the user's eyes and the device in use. If the distance is increased, the size of the fonts should be increased.

The enlargement process is complex and difficult because there are four CSS measurement units that enable the size of the fonts to be enlarged. A decision has to be made regarding which unit should be used. Some measurement units provide for continuity on mobile devices while other measurement units provide for continuity on desktops. For this reason discussions and critiques continue regarding where they should be used.

Basic information has been given below regarding CSS measurement units which enable enlargement of fonts.

(a) "Px" is the name of each and every point on the screen of any device. Px is the structural unit which enables the concept of resolution to be formed. Good results can be attained at certain resolution values. However unwanted images may be formed when resolution values are changed. It diminishes the scalability of an image and is not appropriate for the responsive web design approach.

(b) "Em" is the unit of the font size of written material used in websites. It is scalable. One em is equal to the font size defined for a template. For example, a font size defined for a template as $12 \mathrm{pt}$ is equal to $1 \mathrm{em}$, similarly $2 \mathrm{em}$ is equal to $24 \mathrm{pt}$. This measurement unit is used widely because it is scalable and can be used in mobile devices.

(c) "Pt" is the font measurement unit traditionally used in printed multimedia. $\mathrm{Pt}$ is equal to one of seventy-two parts of an inch. Since the pt measurement unit is a fixed length just as the px measurement unit is, it is not scalable.

(d) The "\%" sign is the same as the em measurement unit with the exception of one difference. The difference is that while the em measurement unit grows linearly, the \% unit grows in squares. This situation sometimes leads to results that designers do not want. When these technical properties are kept in mind, the em measurement unit is the unit most widely used by designers. It is also the measurement unit which yields the most predictable results.

The $\%$ measurement unit is used by designers, who have a stronger grasp of this unit's behavior, when they are designing more legible websites. The other two measurement units are generally used by less experienced designers and this decreases the scalability of the website under design.

\section{Flexible Multimedia Components}

Hyper Text Markup Language (HTML) pages and CSS Technologies are very quickly uploaded by browsers.[9] However webpage contents do not consist solely of text information. Everyday many various multimedia are uploaded to the WWW (WorlWideWeb). For example, over 300 million photographs are uploaded to Facebook Daily [10]. Almost all websites use multimedia. The existence of vast numbers of multimedia components has the effect of slowing down the process of uploading 
webpages. However increasing the band width and solving this problem in this manner still poses a great infrastructure problem. Therefore, all multimedia components should be compressed and possess a specific ratio. This is how it should be presented to the end users.

Today almost all smart phones have screens with DPI (Dots Per Inch) properties. The most advanced models have FHD (Full High-Definition) resolution. Yet FHD is not even the most popular resolution for desktop screens. Reading texts on these types of screens is quite easy for the user because the outer edges of the components and letters are not fine cut. However symbols and images appear blurred when they are enlarged to screen size. This problem arises not only with mobile devices but also with desktop and mobile computers.

There are some alternatives to approaching this problem. The first alternative is to use photographs that are larger than needed for the standard monitor. Later on, the photograph is going to be seen in a one to one ratio on FHD screens and in a smaller ratio on standard screens. For example, on the Apple Inc. official website, all graphic files are twice the width and height of normal computer screens. Of course this approach should be handled with great caution because this situation increases the information size and server load. Nevertheless, other designers should utilize Apple's approach for certain pictures that are in their website design. This approach increases the investment cost but on the other hand provides ease of usage, visual quality and high resolution support.

Another solution that should definitely be adapted is to avoid the use of cellular graphics wherever possible, including SVG (Scalable Vector Graphics) with mobile support. This situation leads to the necessity of using vector objects directly on website pages. When using this approach, users not only see high quality images, they will also be exempt from a great deal of data traffic because vector image sizes are much smaller than cellular images.

\section{Flexible Images}

One of the most important aspects of responsive web design is that it allows for images to change size according to the device screen and browser window size. The width and height of images are determined by default according to the use of the pixels. Scaling is not flexible with this method because it fixates the size of the image. Proportional values need to be used in order to make the image size flexible. This approach not only renders the images flexible, it also eases their control.

Today there are many formats of image files being used in the web environment. The discussion on which ones should be used in responsive web design continues among designers and programmers. The PNG (Portable Network Graphics) format seems to be the best solution because it supports lossless data compression and transparency. Thus PNG is the best format for small graphics used to decorate websites. JPEG (Joint Photographic Experts Group) is the most appropriate solution for bigger sized images and photographs. JPEG is a file format method for lossy compression. Other graphic formats possess different disadvantages. Thus JPEG and PNG are the best choices for responsive web design.

\section{Scalable Vector Images}

Scalable vector images are images that are defined by mathematical functions. Their sizes can be ignored because the images have been formulated with vectors. Scalable vector images can be scaled in all directions without loss of quality. The advantages in using scalable vector images are: (a) They are automatically scaled without quality loss. (b) Their sizes are defined in CSS pixels. (c) They are supported by all modern browsers. (d) Their file size is relatively smaller and they can be compressed. The biggest problem with scalable vector images is that they are not supported by old generation browsers. 

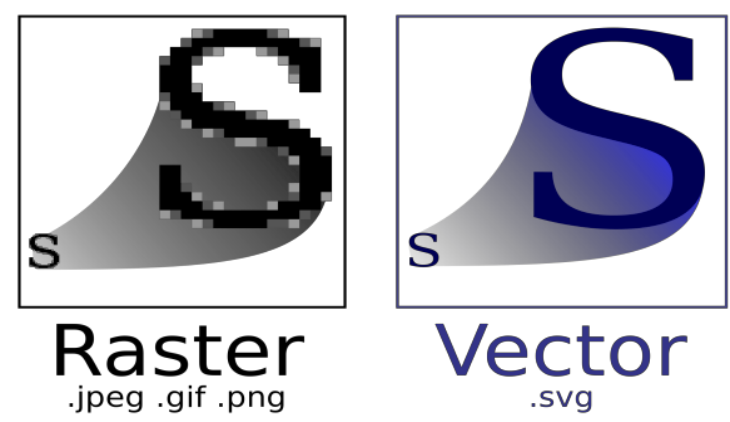

Figure 7 The Difference between Scalable Vector Images and Standard Images

\section{Flexible Videos}

There are two different situations when using flexible videos in responsive design. If the video is being uploaded from our server, the video is treated as any image would be and its size is determined proportionally. If the video is being uploaded from a different source, it is placed entirely in a segment and the dimensions of this segment are determined proportionally. After determining the areas where the video is viewed, the display unit presents the user the option of choosing a video resolution.

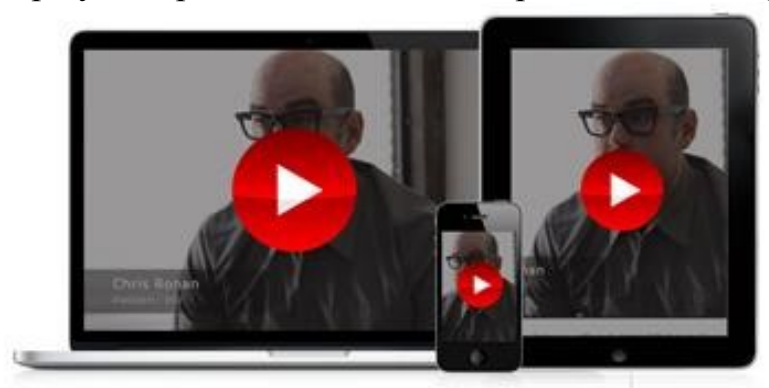

Figure 8 Viewing Flexible Videos on Different Devices

\section{Touchscreen Compatibility}

The goal of the touchscreen compatibility endeavor is to make the design work effectively on mobile devices. Usually it is difficult for mobile device users to interact with a component or a hyperlink. The reason for this is that the necessary touchscreen compatibility procedures were not taken into account during the design stage. The point that has to be taken into account at this stage of the work is that the inner side spaces of the components and hyperlinks have to be 44 pixels in size. This number corresponds to the area contacted on the screen when touched by an average person's finger. In order to carry out this procedure, the side filling and side space properties of the components should be designed such that they are scalable. If this rule is followed during the design stage, an interface that is easy to interact with on both mobile and desktop devices will be created.

\section{Old Generation Browser Support}

Responsive web design works through multimedia queries which are technically supported by CSS3[11]. However CSS3 is not supported by some of the old generation browsers. This factor limits the use of the responsive web design approach. For example, Microsoft Internet Explorer 8 which went on-line eleven years ago and which is not supported by CSS3 is still being used today. However it does not satisfactorily display websites which have been designed with the responsive design approach. The reason this browser is still in use is that it is embedded in the Microsoft XP operating system. The use of XP has de-escalated since Microsoft ceased to support it as of April, 2014. Thus the use of the old generation browser Explorer 8 is also on the decline.

In the case that the support of old generation browsers is desired, it is possible via various technical solutions and by lengthening the time needed to write the code. These technical solutions usually include open source codes and are not entirely dependable. These technical solutions enable multimedia queries to be implemented via JavaScript routines. Thus consequently they can be used on all old generation browsers that can run JavaScript codes. They introduce an additional load to a website and may lead to security vulnerability. 


\section{Responsive Mobile Routing}

The routing process that is performed on mobile devices is a sensitive and difficult to achieve stage in responsive web design[12]. Since the screens of mobile devices are small in comparison to desktop devices, locating and adjusting the dimensions of routing components such as menus present a problem for designers. In order to solve this problem, the proportional dimensions of routing components and contents should be determined and coded in accordance with the function of the website. As a general solution, small menu tokens are embedded in the segments that are located on the sides of the viewport. When these tokens are contacted, the menus become larger. As a result of this approach, a large area will be available for the contents. Furthermore interacting with the menu will be simplified for the user. Another topic that has to be kept in mind is managing the changes that occur in the ratios of the viewport, namely the changes which take place with lateral and vertical positional changes. The differences that arise when the sizes or dimensions change can be eliminated. One approach to solve this difference is to use components that are close to the ratios of a square. Another solution to this problem is to use two different templates. However this approach increases the bulk of information which the website weighs down on the device.

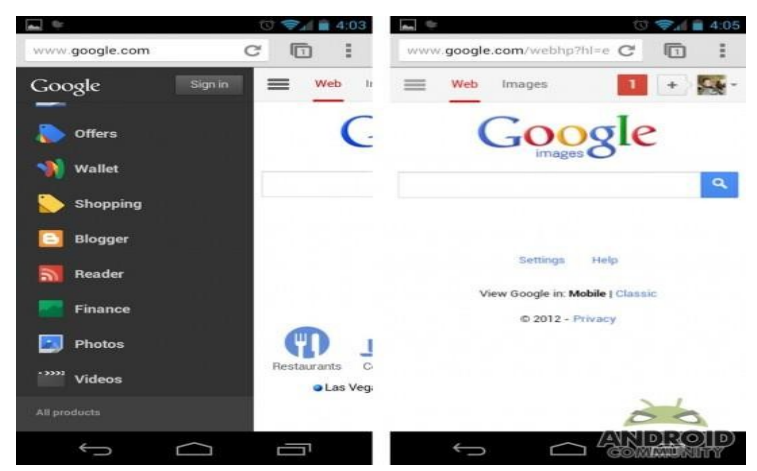

Figure 9 Mobile Routing Element

\section{RESPONSIVE WEB DESIGN FRAMEWORKS}

Templates coded solely in HTML and CSS require lengthy time and extensive manpower. One of the problems of this approach is the length of time needed to develop them[13]. One way of overcoming this problem is by using ready-made code builders and development frameworks. These development frameworks present designers and programmers with pre-made codes and directions. Thus they target to diminish the repetitive workload carried on during the development stage. The target of code builders is to diminish the duration of the development process by transforming the visual appearance of the design into a code.

The top ten development frameworks as of 2015 have been chosen according to the number of times they have been downloaded and used. In order of first to tenth, these are:

The top ten development frameworks as of 2015 have been chosen according to the number of times they have been downloaded and used. In order of first to tenth, these are:

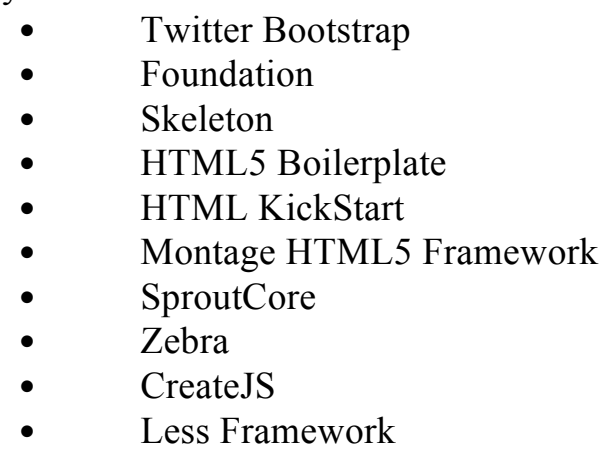

These development frameworks have been compared with respect to responsive web design principles, the size of the community they possess, and the number of documentations. 
The first aspect that catches attention when development frameworks are analyzed is that they have successfully and entirely incorporated the basic necessities and principles. Among the packages analyzed, all the frameworks possessed the necessary grid structure and responsive web template. The analysis of this grid structure triggers being media-independent or the compatibility among media. When the subject is viewports, the differences between frameworks and their inadequacies rise to the surface. When different image sizes are correlated with old versions of web browsers, there are few frameworks which maintain consistency. The display and usage of multimedia items on the web is another important matter. The barrenness of frameworks regarding this matter also catches the eye. Problems sometimes arise even with Twitter Bootstrap which is the most qualified and most comprehensive framework on the list. At this point of the design process, the aid of third party solutions becomes important. Again, Twitter Bootstrap possesses the most extensive libraryarchive related to this topic.

All developmental frameworks are built up on an up to date and popular web technology, namely HTML5[14]. This is an important factor for projects to be sustainable. On the other hand, some packages still do not support CSS3 while some packages are integrated solely with the jQuery library; these situations can be considered as handicaps. The fact that Twitter Bootstrap, in particular, possesses values identical to the jQuery structure, facilitates the developers' work. It is an important issue that rich and complicated items are included in packages. At this point, Bootstrap's shortcomings arise to the surface. Packages that include more complex interface elements such as summary tables and color choice pallets are available. Consequently making a correct analysis in accordance with the project and conducting research on pre-requisites are important.

\section{CONCLUSIONS AND RECOMMENDATIONS}

The findings of the comparison of responsive web design frameworks is as below: Before choosing a package, a requirement analysis should definitely be carried out. The properties of the packages should be studied according to this analysis and the choice should be made accordingly.

When choosing, it is necessary to take into account if it possesses compatibility with JavaScript libraries which are widely used. In order for the project to progress consistently, it is important to prefer packages that are compatible with widely preferred packages, particularly such as jQuery. The preferred package should be prepared according to the first media of the project to be developed. For example, the framework for a project that will be prepared primarily for mobile devices would be a framework with powerful mobile qualities.

For projects with concentrated contents and mainly content presentation, frameworks with a wide and multi-grid system (12 or more) should be preferred. If it is a comprehensive and long-term project, in order to maintain a sustainable project, it becomes important if the packages can be personalized. The need for high performance and speed are also differentiating properties among frameworks. For projects where the design of the interface is not important and practical, fast solutions are required, high performance frameworks can be preferred.

Even if responsive web design solutions require more manpower in the first steps of the design process, they should be used in modern website designs because they have a higher potential of being sustainable. Since the capabilities of browsers and mobile devices increase day by day, web sites designed with this approach provide users with ease and quality of experience. Since this approach is accepted by search motors as a criterion of quality, access is easier. This situation has a positive effect on the number of users. This is an approach that should be used by companies and individuals who want to present a modern website of good quality, fixed user experience, and also complete the design process in a single stage. Responsive web design has become a website rule in our day and is becoming used more and more widely. 


\section{REFERENCES}

[1] Kadlec, Tim, 2013. Implementing Responsive Design: Building sites for an anywhere, everywhere web (Voices That Matter).

[2] Cochran, David, 2012. Twitter Bootstrap Web Development How-To.

[3] Getting Started with Responsive Web Design - A Dummies Guide, 2015.

http://www.labnol.org/internet/responsive- webdesign-faq/21361/. 25/12/2015

[4] Beginner's Guide to Responsive Web Design - Treehouse Blog, 2015.

http://blog.teamtreehouse.com/beginners-guideto- responsive-web-design. 24/12/2015

[5] Gasston, Peter, 2013. The Modern Web: Multi- Device Web Development with HTML5 CSS3, and JavaScript.

[6] LePage, Pete ,2014. Use CSS media queries for responsiveness.

[7] WordPress. Using Media Queries with CustomCSS. : https://en.support.wordpress.com/ customdesign/custom-css-media-queries/. 23/12/2015

[8] Hay, Stephen, 2013. Responsive Design Workflow.

[9] HTML5 - Responsive Web Design. http://msdn.microsoft.com/enus/magazine/hh653584.aspx . $24 / 12 / 2015$

[10] Pingdom AB 2013. Internet 2012 in numbers:https//royal.pingdom.com/2013/01/16/inte rnet2012-in-numbers/. 26/12/2015

[11] Robbins, Jennifer 2012. Learning Web Design: A Beginner's Guide to HTML, CSS, JavaScript, and Web Graphics.

[12] Morton, Lisa. Responsive Web Design - Why it Matters, Why You Need it.

[13] Lynch, Patrick, 2009. Web Style Guide: Basic Design Principles for Creating Web Sites.

Marcotte, E. ,2011. Responsive Web Design

[14] Gustafson, Aaron, 2011. Adaptive Web Design: Crafting Rich Experiences with Progressive

Enhancement. 


\section{Comparison of Responsive Web Design Frameworks}

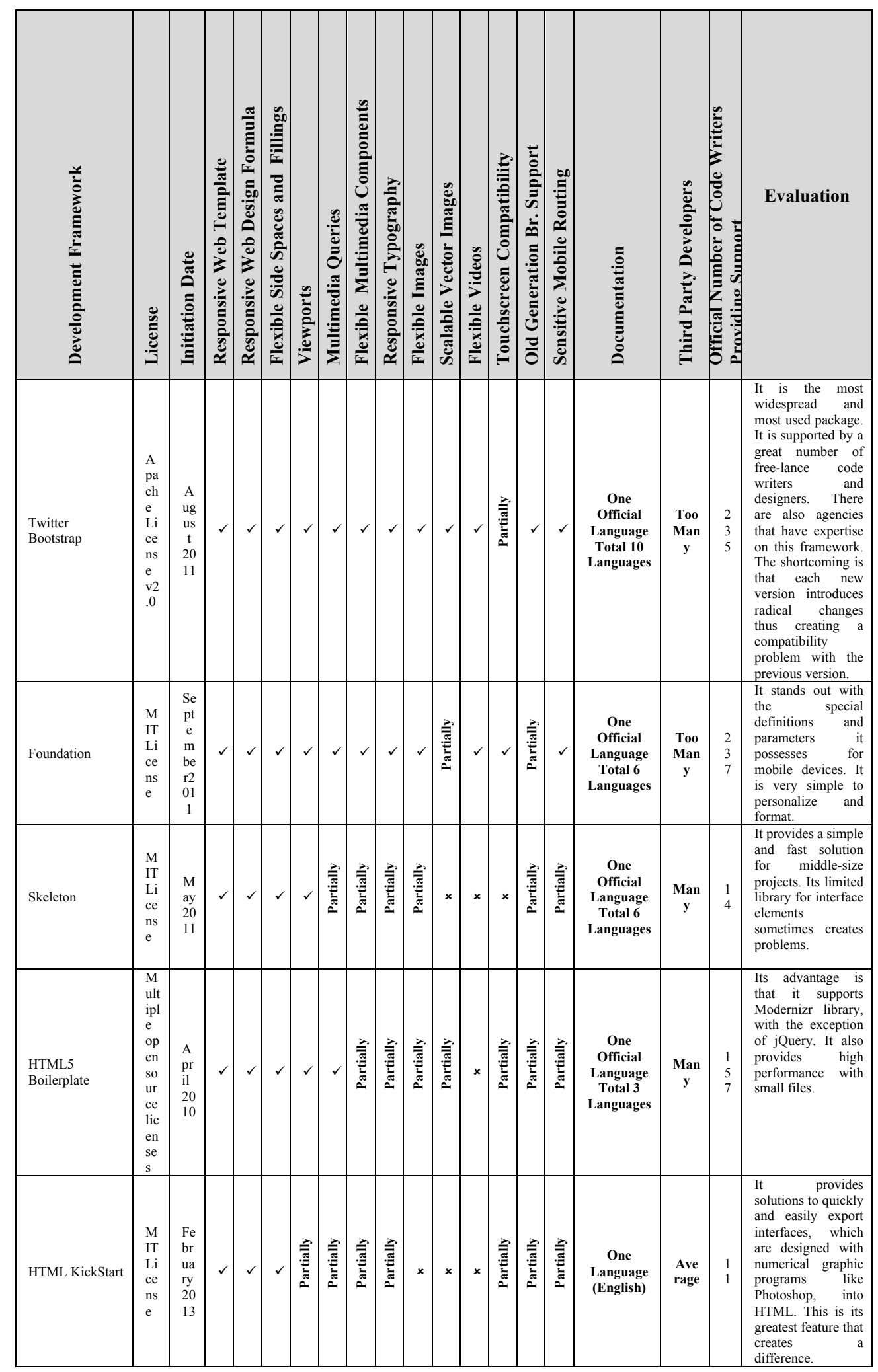


The Turkish Online Journal of Design, Art and Communication - TOJDAC January 2017 Volume 7 Issue 1

\begin{tabular}{|c|c|c|c|c|c|c|c|c|c|c|c|c|c|c|c|c|c|c|c|}
\hline $\begin{array}{l}\text { Montage } \\
\text { HTML5 } \\
\text { Framework }\end{array}$ & $\begin{array}{l}\mathrm{B} \\
\mathrm{S} \\
\mathrm{D} \\
\mathrm{Li} \\
\mathrm{ce} \\
\mathrm{ns} \\
\mathrm{e}\end{array}$ & $\begin{array}{l}\text { Ju } \\
\text { ly } \\
20 \\
12\end{array}$ & $\checkmark$ & $\checkmark$ & $\checkmark$ & $\checkmark$ & $\checkmark$ & $\checkmark$ & 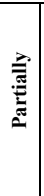 & 总 & 总 & $\checkmark$ & D. & 竞 & 疍 & $\begin{array}{c}\text { One } \\
\text { Language } \\
\text { (English) }\end{array}$ & $\begin{array}{c}\text { Ave } \\
\text { rage }\end{array}$ & $\begin{array}{l}2 \\
4\end{array}$ & $\begin{array}{l}\text { It provides a } \\
\text { practical solution } \\
\text { for applications } \\
\text { that require high } \\
\text { performance. }\end{array}$ \\
\hline SproutCore & $\begin{array}{l}\mathrm{M} \\
\mathrm{IT} \\
\mathrm{Li} \\
\mathrm{ce} \\
\mathrm{ns} \\
\mathrm{e}\end{array}$ & $\begin{array}{l}20 \\
10\end{array}$ & $\checkmark$ & $\checkmark$ & $\checkmark$ & $\checkmark$ & $\checkmark$ & $\checkmark$ & $\checkmark$ & $\checkmark$ & $\checkmark$ & $x$ & $x$ & 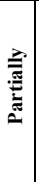 & 吾 & $\begin{array}{c}\text { One } \\
\text { Language } \\
\text { (English) }\end{array}$ & $\begin{array}{l}\text { Ave } \\
\text { rage }\end{array}$ & $\begin{array}{l}1 \\
2 \\
6\end{array}$ & $\begin{array}{l}\text { It possesses a } \\
\text { successful core for } \\
\text { creating complex } \\
\text { web applications. }\end{array}$ \\
\hline Zebra & $\begin{array}{l}\mathrm{L} \\
\mathrm{G} \\
\mathrm{P} \\
\mathrm{L}\end{array}$ & $\begin{array}{l}\mathrm{N} \\
\mathrm{ov} \\
\mathrm{e} \\
\mathrm{m} \\
\mathrm{be} \\
\mathrm{r} 2 \\
01 \\
2\end{array}$ & $\checkmark$ & $\checkmark$ & $\checkmark$ & $\checkmark$ & $\checkmark$ & $\checkmark$ & $\checkmark$ & $\checkmark$ & $x$ & $x$ & $x$ & $x$ & $x$ & $\begin{array}{c}\text { One } \\
\text { Language } \\
\text { (English) }\end{array}$ & $\begin{array}{c}\text { Ver } \\
\text { y } \\
\text { Few }\end{array}$ & 4 & $\begin{array}{l}\text { It possesses } \\
\text { interface elements, } \\
\text { such as color } \\
\text { palette and tree } \\
\text { navigation, which } \\
\text { are rich and very } \\
\text { functional. It will } \\
\text { become much more } \\
\text { powerful } \\
\text { compatibility if } \\
\text { problems are } \\
\text { solved. }\end{array}$ \\
\hline CreateJS & $\begin{array}{l}\mathrm{U} \\
\mathrm{nk} \\
\text { no } \\
\mathrm{w} \\
\mathrm{n}\end{array}$ & $\begin{array}{l}\text { M } \\
\text { ar } \\
\text { ch } \\
20 \\
12\end{array}$ & $\checkmark$ & $\checkmark$ & $\checkmark$ & $x$ & $\checkmark$ & $\checkmark$ & $x$ & $x$ & $x$ & $x$ & $x$ & $x$ & $x$ & $\begin{array}{c}\text { One } \\
\text { Language } \\
\text { (English) }\end{array}$ & $\begin{array}{c}\text { Ver } \\
\text { y } \\
\text { Few }\end{array}$ & $\begin{array}{l}1 \\
4\end{array}$ & $\begin{array}{lr}\text { It is a package } \\
\text { specialized } \\
\text { particularly } \\
\text { multimedia } \\
\text { elements such as } \\
\text { sound } & \text { and } \\
\text { animation. } & \text { It } \\
\text { possesses } & \text { a } \\
\text { powerful } & \\
\text { JavaScript } & \\
\text { infrastructure. } & \\
\end{array}$ \\
\hline Less Framework & $\begin{array}{l}\mathrm{M} \\
\mathrm{IT} \\
\mathrm{Li} \\
\mathrm{ce} \\
\mathrm{ns} \\
\mathrm{e}\end{array}$ & $\begin{array}{l}\text { Ju } \\
\text { ne } \\
20 \\
11\end{array}$ & $\checkmark$ & $\checkmark$ & $\checkmark$ & 尝 & 竧 & 离 & 咅 & $x$ & $x$ & $x$ & $x$ & $x$ & $x$ & $\begin{array}{c}\text { One } \\
\text { Language } \\
\text { (English) }\end{array}$ & Few & 2 & $\begin{array}{l}\text { An extensive } \\
\text { number of new } \\
\text { features have been } \\
\text { added within a } \\
\text { short span of time } \\
\text { to the framework, } \\
\text { which is set up } \\
\text { mainly on a grid } \\
\text { system. } \\
\text { promising future is } \\
\text { in store if it } \\
\text { continues at this } \\
\text { pace. }\end{array}$ \\
\hline
\end{tabular}

